\title{
Development of Motor Brake System for Explosion-Proof Elevator
}

\author{
Young-Joon Ko, Chang-Ki Hong, Soo-Chul Hwang, Kwan-Hee Han
}

\begin{abstract}
Recently, we are using explosion-proof elevators not only in industrial areas where there is a risk of gas leakage, but also in poor atmospheric conditions. Therefore, there is an increasing need for development an explosion-proof elevator with more safety. Therefore, this study developed an electric motor brake with high possibility of arc in the elevator parts as an explosion - proof type. For this purpose, we analyzed patented technology of elevator and patent of explosion proof technology. Based on the results, we developed an electric motor brake for an explosion-proof elevator. The technology also focuses on improving the housing and solenoid of the brakes and shows improved explosion protection compared to conventional brakes. As a result of analyzing the patent of the explosion proof technology, it was analyzed that the frame proof enclosure of the brake of the explosion type elevator is effective. The housing of the electromagnetic brake for the explosion-proof elevator was analyzed to be the most preferable structure with the explosion proof structure. Based on the above analysis, this paper defined the locking mechanism of the brakes and design the stable structure of the brakes. In this study, the optimum structure of the electromagnetic brake for the explosion proof elevator was found to be the explosion proof structure, and the existing elevator explosion proof technology focused only on the structure of the switch was extended to improve the explosion proofing function by improving the housing.
\end{abstract}

Keywords : brake housing, explosion-proof elevator, explosion-proof brake, pressure-resistant explosion-proof structure

\section{INTRODUCTION}

In the meantime, explosion-proof technology has been developed in various industries. Among them, in the case of elevators, explosion-proof elevators are applied and operated in some administrative districts where petrochemical plants, painting plants, gas handling facilities, grain warehouses, milling factories and textile factories are concentrated in Korea. The total number of lifts installed in Korea is 683,641. Among them, 23,962 cargo elevators, mainly explosion-proof type elevators, are operated, and about 2,500 of $1 \%$ of explosion-proof type elevators are operated. Fig. 1 shows the installation status of elevators in Korea. The explosion-proof elevator is a facility that plays an important role in the safety of industrial facilities such as LNG and plants. Up to now, the

Revised Manuscript Received on July 22, 2019.

Young-Joon Ko, Lift Engineering Department, Korea Lift College, Geochang, Republic of Korea. Email: yjoonko@klc.ac.kr

Chang-Ki Hong, Business Department, Dae O Precision Engineering Co., Ltd., Seoul, Republic of Kore. Email: dillyhong@ daeo.co.kr

Soo-Chul Hwang, Lift Engineering Department, Korea Lift College, Geochang, Republic of Korea. Email: elisoo@nate.com Gyeongsang Nat'l Univ, Jinju, Republic of Korea. Email: hkhan@gnu.ac.kr
Kwan-Hee Han*, Dept. of Industrial \& Systems Engineering,

elevator has been focused on the development of a component called an explosion-proof switch, which is one of the components of the elevator. However, recent trends in the company have raised the technology of explosion protection to more than protection of the equipment. There are roughly four explosion-proof elevator manufacturers in Korea, mainly selling to domestic demand companies, and exports are also sold in connection with domestic demand companies.

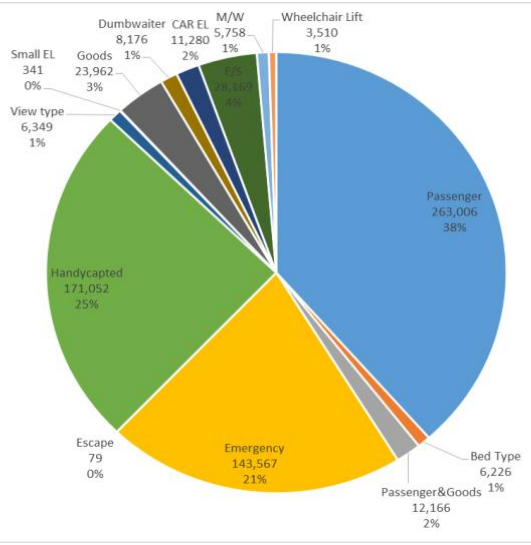

Fig. 1. Status of Elevator Installation in Korea (Korea Elevator Safety Agency)

Explosion-proof elevators installed in Korea are mostly Ex d IIB T4 in Zone 2 area. Foreign companies are Partial Ex. Proof Type (partial explosion proof), Full Ex. Proof Type (total explosion proof). It is manufactured according to the grade of EX IIA and IIB (temperature lower than $40^{\circ} \mathrm{C}$, temperature lowered by installing air conditioner when it is over $40^{\circ} \mathrm{C}$ ) in Zone 1 and Zone 2 regions. Zone 1 is a place where explosive gas accumulates under normal conditions and may become a dangerous concentration, and where maintenance repair or explosive gas may gather to create a dangerous concentration, a place where explosive gas may gather and become a dangerous concentration to be. Zone 2 refers to a place where dangerous atmosphere can exist for a short period of time in a state beyond the normal maintenance and management state [1]. As of 2016, the cumulative number of overseas elevators will be 14,000,000 and the number of new installations expected to be $1,000,000$ the number of explosion-proof elevators in the total number of overseas elevators installed is around $0.1 \%$, with 14,000 units being installed [2]. In addition, in accordance with the trend of strengthening the role of the evacuation elevator to prepare for the disaster such as fire according to the safety awareness of the public recently, 
technology development focused on securing the safety of the disaster area and the spread of the technology of the explosion- It is actively being done. Therefore, this study analyzes patent-related explosion-proof technology in related industries until now and compares the composition of elevator brakes among the components of the elevator, which is the most necessary component of the elevator, to the international standard requirements through the fire resistance test of the brake housing design the optimal brake design standards for explosion-proof elevators.

\section{MATERIALS AND METHODS}

\section{Patent analysis}

Table- I: Analysis of Patents about Elevator Motor \& Brake Technology

\begin{tabular}{|c|c|c|c|c|c|}
\hline NO & $\begin{array}{l}\text { DETAIL } \\
\text { SORT }\end{array}$ & NATIONS & $\begin{array}{l}\text { PUBLIC } \\
\text { ISSUED } \\
\text { NO. }\end{array}$ & APPLICANT & NAME OF INVENTION \\
\hline 1 & MOTOR & $\mathrm{KR}$ & $\begin{array}{c}2012- \\
0129866\end{array}$ & $\begin{array}{l}\text { DEMAG CRANES \& } \\
\text { COMPONENTS }\end{array}$ & $\begin{array}{l}\text { CHAIN HOIST HAVING } \\
\text { A SLIP CLUTCH }\end{array}$ \\
\hline 2 & BOX TYPE & JP & $\begin{array}{c}2000- \\
238983\end{array}$ & HITACH & $\begin{array}{c}\text { ELEVATOR UNIT } \\
\text { (ELEVATOR DEVICE) }\end{array}$ \\
\hline 3 & BOX TYPE & $\mathrm{JP}$ & $\begin{array}{c}2002- \\
238984\end{array}$ & $\begin{array}{l}\text { MITSUBISHI } \\
\text { ELECTRIC }\end{array}$ & $\begin{array}{c}\text { WINCH FOR ELEVATOR } \\
\text { (ELEVATOR WINCH) }\end{array}$ \\
\hline 4 & MOTOR & $\mathrm{EP}$ & 2325983 & $\begin{array}{l}\text { MITSUBISHI } \\
\text { ELECTRIC }\end{array}$ & HOIST FOR ELEVATOR \\
\hline 5 & BOX TYPE & $\mathrm{CN}$ & 10113966 & HITACH & HOSTING MACHINE DEVICE FOR ELEVATOR \\
\hline 6 & BOX TYPE & $\mathrm{CN}$ & 1469837 & $\begin{array}{l}\text { MITSUBISHI } \\
\text { ELECTRIC }\end{array}$ & ELEVATOR HOIST \\
\hline 7 & MOTOR & $\mathrm{CN}$ & 105531912 & OTIS ELEVATOR & $\begin{array}{c}\text { FOR ELEVATOR SYSTEMCOOLING OF THE } \\
\text { MACHINE } \\
\text { (COOLING OF MACHINE FOR ELEVATOR } \\
\text { SYSTEM) } \\
\end{array}$ \\
\hline 8 & BRAKE & $\mathrm{CN}$ & 102358555 & $\begin{array}{l}\text { Hunan Chuangan } \\
\text { Frameproof Eletric } \\
\text { Appliances } \\
\end{array}$ & MINE HOISTING WINCH \\
\hline 9 & BRAKE & $\mathrm{KR}$ & 1361367 & $\begin{array}{l}\text { MITSUBISHI } \\
\text { ELECTRIC }\end{array}$ & BRAKE DEVICE FOR HOIST FOR ELEVATOR \\
\hline 10 & BRAKE & $\mathrm{KR}$ & 1219236 & $\begin{array}{l}\text { MITSUBISHI } \\
\text { ELECTRIC }\end{array}$ & HOIST FOR ELEVATOR \\
\hline 11 & BRAKE & KR & 621242 & $\begin{array}{l}\text { MITSUBISHI } \\
\text { ELECTRIC }\end{array}$ & HOIST AND MOTOR FOR ELEVATOR \\
\hline 12 & BRAKE & $\mathrm{KR}$ & 623168 & $\begin{array}{l}\text { MITSUBISHI } \\
\text { ELECTRIC }\end{array}$ & BRAKE DEVICE OF ELEVATOR HOIST \\
\hline 13 & BRAKE & $\mathrm{KR}$ & 441043 & $\begin{array}{l}\text { HYUNDAI } \\
\text { ELEVATOR }\end{array}$ & SLIMMING TYPE TRACTION MACHINE \\
\hline 14 & BRAKE & $\mathrm{JP}$ & $\begin{array}{c}2016- \\
130152\end{array}$ & HITACH & $\begin{array}{c}\text { TRACTION MACHINE FOR ELEVATOR \& } \\
\text { INSTALLATION METHOD OF TRACTION } \\
\text { MACHINE FOR ELEVATOR }\end{array}$ \\
\hline 15 & BRAKE & $\mathrm{JP}$ & 4658063 & $\begin{array}{l}\text { MITSUBISHI } \\
\text { ELECTRIC }\end{array}$ & MACHINE ROOMLESS ELEVATOR UNIT \\
\hline 16 & BRAKE & $\mathrm{JP}$ & 4963153 & $\begin{array}{l}\text { MITSUBISHI } \\
\text { ELECTRIC }\end{array}$ & MACHINE ROOMLESS ELEVATOR \\
\hline 17 & BRAKE & $\mathrm{JP}$ & 4882195 & $\begin{array}{l}\text { MITSUBISHI } \\
\text { ELECTRIC }\end{array}$ & ELEVATOR EQIPMENT \\
\hline 18 & BRAKE & $\mathrm{JP}$ & $\begin{array}{c}2013- \\
144585\end{array}$ & $\begin{array}{l}\text { MITSUBISHI } \\
\text { ELECTRIC }\end{array}$ & $\begin{array}{l}\text { DISK BRAKE FOR ELEVATOR TRACTION } \\
\text { MACHINE \& METHOD OF DUST REMOVAL }\end{array}$ \\
\hline 19 & BRAKE & JP & $\begin{array}{c}2006- \\
298569\end{array}$ & $\begin{array}{l}\text { MITSUBISHI } \\
\text { ELECTRIC }\end{array}$ & BRAKE DEVICE OF ELEVATOR WINCH \\
\hline 20 & BRAKE & $\mathrm{JP}$ & $\begin{array}{c}2012- \\
035971\end{array}$ & $\begin{array}{c}\text { TOSHIBA } \\
\text { ELEVATOR }\end{array}$ & $\begin{array}{l}\text { BRAKE INSTALLATION TOOL OF ELEVATOR } \\
\text { WINCH }\end{array}$ \\
\hline 21 & BRAKE & $\mathrm{EP}$ & 963942 & KONE & $\begin{array}{l}\text { HOLDING BRAKE FOR A TRACTION SHEAVE } \\
\text { ELEVATOR }\end{array}$ \\
\hline
\end{tabular}

Technology development for elevators has been steadily taking place at home and abroad. Especially, in recent years, due to the rapid technological change caused by the 4th industrial revolution, technology development in the field of remote prediction preservation has been actively performed. In this study, 43 key patent applications of elevator core were analyzed in 946 patents. As shown in Table 1, 21 key patents in the technology field of Kwang Sang Machine were derived.

No. 1 in Table 1 is the invention for motor clutch with Korean patent [3]. No. 2 is a technology related to elevator devices by Japanese patent [4]. 
No. 4 is a European patent, and Mitsubishi Electric Corporation invented motor technology for elevators [5]. No. 7 is China's patented elevator motor cooling technology [6]. No. 9 is an elevator brake device technology invented by Mitsubishi Electric Company under the Korean patent [7]. No. 14 is a Japanese patent, which is an elevator machine installation technique of brake technology [8]. No. 16 is a Japanese patented elevator brake technology without machine room [9]. No.18 is a Japanese patented method for removing dust from disc type elevator brakes [10]. Most are focused on performance improvement and there is no explosion technology specifically for elevators.

\subsection{OS-Metrix}

OS-Metrix is a technique of patent analysis that derives a combination of skill levels to solve a solution by constructing a patent technology tree as a domain of a solution task and a solution method. In this study, heat dissipation, miniaturization of the motor, and prevention of intrusion of foreign matter are derived as a related problem through the analysis as shown in Fig. 2.

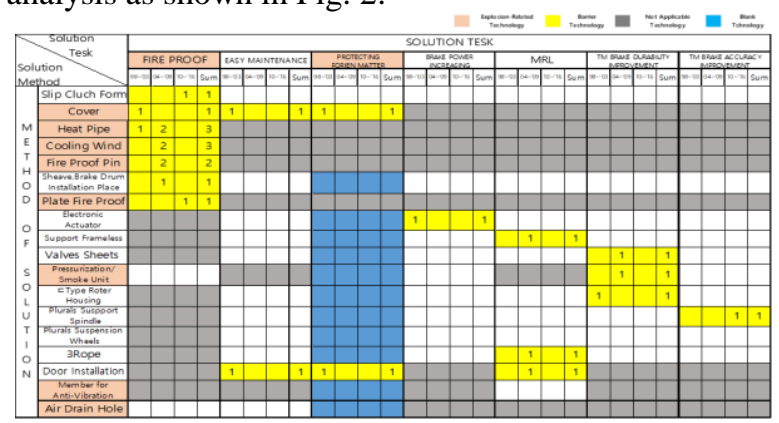

Fig. 2. OS-Metrics for Critical Explosion Technology Analysis

As shown in Fig. 2, the Tech-Tree OS-Matrix was constructed based on 21 core patents. Tech-Tree OS Matrix analysis is a system that analyzes multiple patented technologies that are subject to analysis, row, are mapped to the elements of each matrix. In OS-Metrics, orange color represents the resolution goal and method associated with explosion protection. The number in the yellow box means the number of patents corresponding to the purpose and solution. This means that one patent was registered in 1998 2003 for the technology related to cover for heat dissipation. As shown in Fig. 2, the solution is Cover, Heat Pipe, Cooling Wind, Fire Proof Pin, Plate Fire Proof, Pressurization / Smoke Unit, Member for Anti-Vibration and Air Drain Hole. Among the solutions derived from the OS-Matrix, it is analyzed that it can be implemented with a closed housing structure [prevention of heat / foreign material intrusion / prevention of vibration / prevention of vibration / abrasive powder adhesion], and the enclosed housing structure and related structure The explosion proof structure has characteristics that can be applied to small appliances and it is analyzed to be suitable for the housing of the traction machine brake for the explosion-proof elevator.

\section{Development of Brake for Explosion proof Elevator}

\subsection{Brake Solenoid Construction}
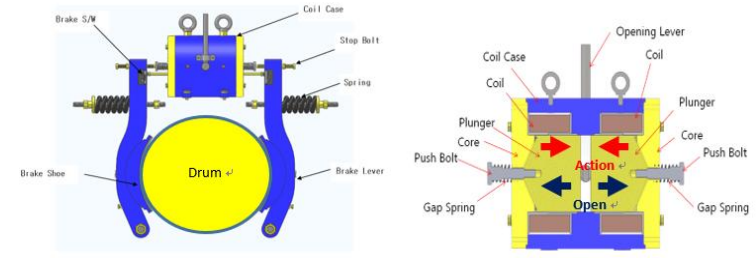

Fig. 3. Electronic Brake \& Solenoid Inside

Fig. 3 shows the solenoid structure of the brake [11]. The solenoid is magnetized or disengaged according to the input of electricity in the closed space, pushing the piston and holding the brake drum by the mechanical force such as spring3. In order to apply the explosion-proof pressure-resistant structure, design specifications of the brake solenoid, which is an electrical ignition source among the component parts of the traction machine brake, were determined. The coil internal voltage is applied at $1,000 \mathrm{~V}$, and the coil insulation is 1,500 M OMEGA, and the open time is determined to be $4 \mathrm{sec}$ or less. The release time is $0.4 \mathrm{sec}$ or less, the coil temperature is 70 or less, and EX.d IIB + H2 + T4.

\subsection{Brake Explosion Test}

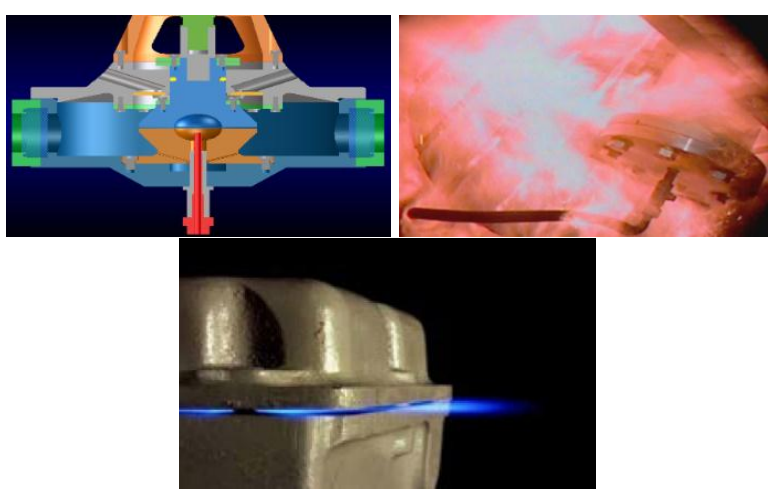

Fig. 4. Flame Propagation Risk Analysis of Flame Joints

As shown in Fig. 4 and Fig. 5, the compliance test of the flam-proof enclosure explosion-proof structure required by IEC 60079-0 and IEC 60079-1 was carried out [12,13]. Each test item is flame-path flame propagation analysis, mechanical strength.

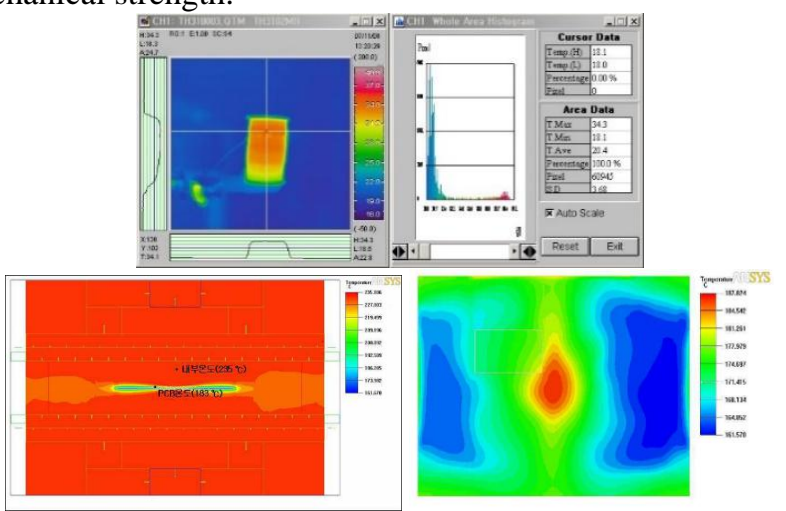

Fig. 5. Temperature Grade (T-grade) Conformance Analysis Due to Heat Dissipation 
analysis, temperature rise $(\Delta \mathrm{t})$ evaluation and temperature grade $(\mathrm{T} 4 \sim 6)$ compatibility test considering environmental conditions. Through this verification test, the risk avoidance design was performed for the pressure suitable for the standard allowable value of the explosion proof structure.

2.3 Brake Housing Optimal Design Brake Explosion Test

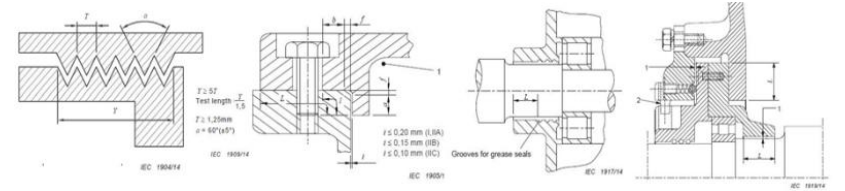

Fig. 6. Detailed Design and Evaluation of Explosion Proof Structure in Accordance with IEC 60079

As shown in Fig. 6, the conceptual design of the explosion-proof traction machine brake and the ISO and IEC explosion-proof standards are summarized as requirements, and the structure of the explosion-proof type elevator is designed according to this standard, the design was proved, and the design of optimum value was derived. Fig. 7 shows the optimized design of the explosion proof structure of the push bolt.
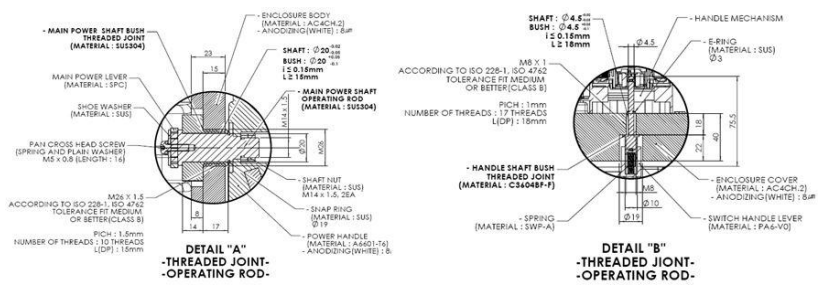

Fig. 7. Optimal Design

\section{RESULT AND DISCUSSION}

Finally, the study focuses on the reinforcement of the housing and the interpretation of the width and length of the bolted joint of the frame becomes important as shown in Fig. 8 .

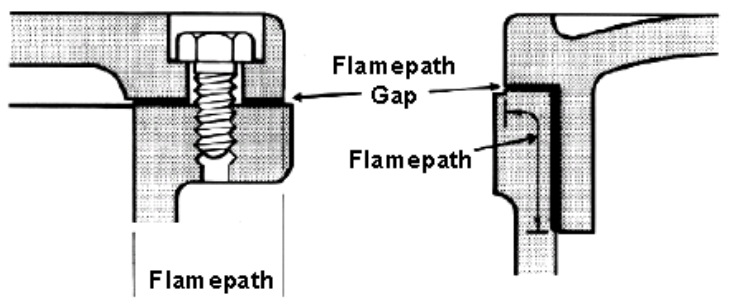

Fig. 2. Flame Path of Push Bolt

In order to meet the standard of explosion proof of the international standard, a safe explosion proof structure was obtained by adjusting the gap of the inlet of the push bolt. Table 2 summarizes the results for each test item.

Table- II: Development Results of Explosion-Proof Core Evaluation Items

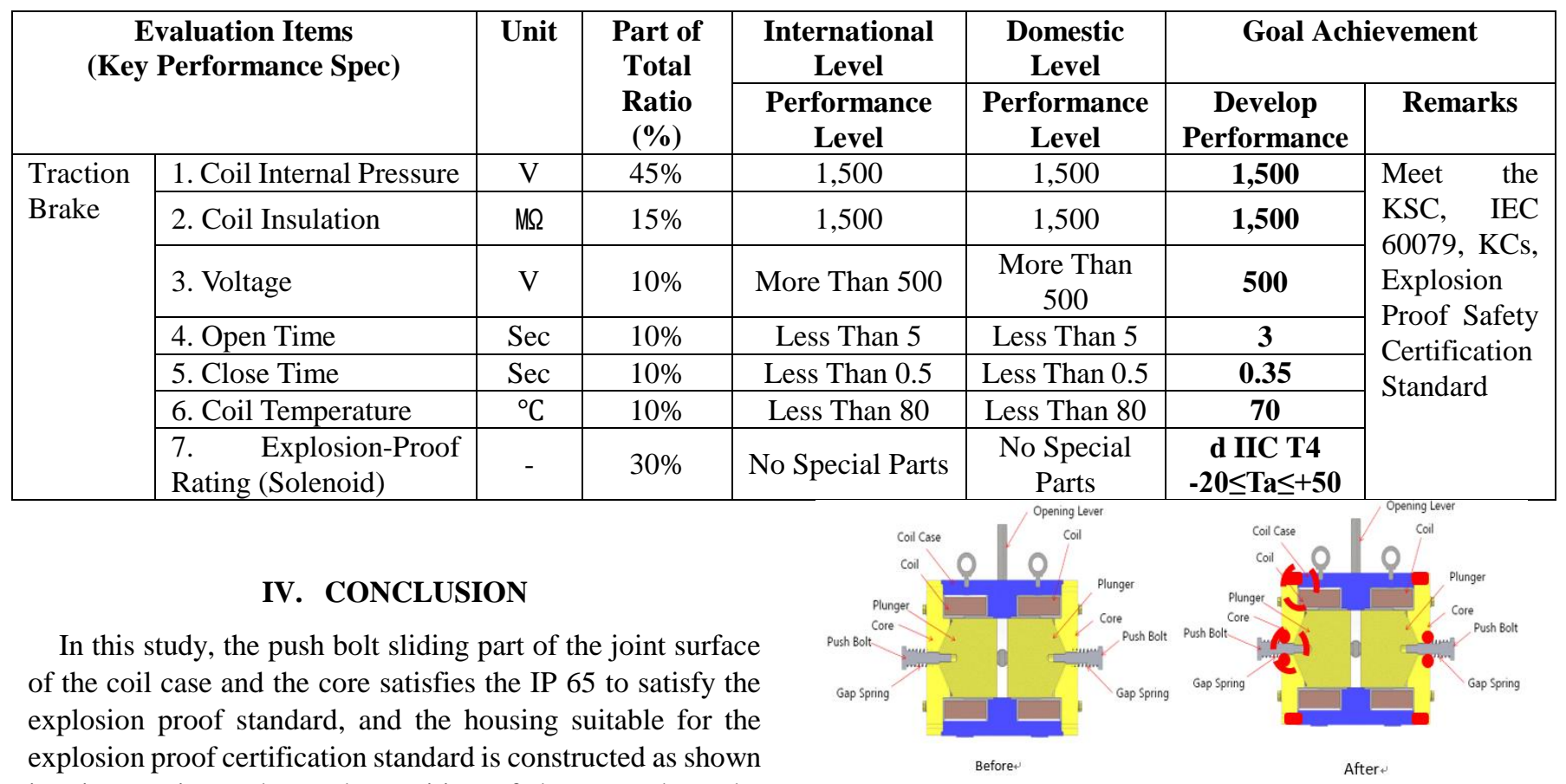
in Fig. 9. Fig. 9 shows the position of the part where the technique of Fig. 8 is applied in the existing brake by the red dotted circle. Through this configuration, we have developed

Fig. 3. Housing Configuration Suitable for Explosion Proof Certification Standard flam-proof enclosure explosion traction machine brake that meets international certification standards by implementing explosion-proof structure.

It is expected that this will 
ensure the stability of the elevator in the dangerous area and it is expected that it will be the standard of stability when installing the explosion-proof elevator in these areas. Until now, conventional brakes have been used in hazardous areas such as Zone 2. And as we have seen, there was no explosion-proof brakes for elevators. To solve this problem, the first explosion-proof structure was applied to the elevator brakes, and even when there was an explosion inside the brake housing, it was not transferred out and the risk was not transferred. The value of this study is an example of applying the explosion proof structure to an elevator brake. Elevator brakes are an important safety part in elevators. In recent years, elevator brakes not only have been responsible for stopping the elevator, but also act as a protective device against unintentional movement. As the utility of these elevator brakes expands, it must be possible to protect the brakes, which are important safety devices for elevators, from exploding or to prevent them from spreading in any harsh environment. Therefore, this study applied the explosion proof structure to the elevator brake. This is considered to be an important cornerstone for the technical development of the protection device or brake.

\section{ACKNOWLEDGMENT}

This study was supported by the industrial core technology development project by Ministry of Trade, Industry and Energy in 2016 2019

\section{REFERENCES}

1. Korean Agency for Technology and Standards, KS C IEC 60079-10-1, Seoul, Republic of Korea, Nov. 2012.

2. NOVONOUS, Global Elevator Market: Forecasts for 2016 and 2020, Karnataka: NOVONOUS, May. 2016.

3. Moll Oliver, "Shriker Lane, Demag Cranes \& Components GmbH. Chain Hoist Having a Slip Clutch," Korea patent KR 1020120129866, Nov. 28, 2012.

4. Nihei Hideki, Nakada Takanori, Arahori Noboru, Nagase Hiroshi, HITACHI. Elevator, “Unit,” Japan patent JP 1223898, Sep. 5, 2000.

5. Kimura Yasuki, Toya Mitsutoshi, Urakawa Hidehiko, Tada Junichi. MITSUBISHI ELECTRIC, "Hoist for Elevator," European Union patent EP 02325983, May. 25, 2011.

6. Hubbard James L., Venturini Marco, Tenti Davide. OTIS ELEVATOR, "for Elevator System Cooling of The Machine," China patent CN 105531912, Apr. 27, 2016

7. Ogawa Goji, MITSUBISHI ELECTRIC, "Brake Device for Hoist for Elevator,” Korea patent KS 1013613670000, Feb. 4, 2014.

8. Tatsuya Matsumoto, Tetsuji Ono, Hiroaki Endo, HITACH, "Traction Machine for Elevator \& Installation Method of Traction Machine for Elevator,” Japan patent JP 28130152, Jul. 16, 2016.

9. Yoshikawa Masayoshi, MITSUBISHI ELECTRIC, "Machine Roomless Elevator,” Japan patent JP 04963153, Apr. 12, 2012.

10. Moll Oliver, Shriker Lane, MITSUBISHI ELECTRIC, "Disk Brake for Elevator Traction Machine \& Method of Dust Removal," Japan patent JP 25144585, Jul. 25, 2013.

11. Lubomir Janovsky., Elevator Mechanical Design Third Edition, U.S: Elevator World Inc., 1999.

12. Korean Agency for Technology and Standards, KS C IEC 60079-0, Seoul, Republic of Korea, May. 2017.

13. Korean Agency for Technology and Standards, KS C IEC 60079-1, Seoul, Republic of Korea, Jan. 2019.

\section{AUTHORS PROFILE}

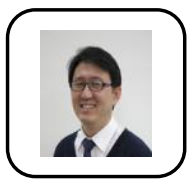

Young-Joon Ko

Feb. 1999: Department of Electrical Engineering (Anyang University)

October 2010: Graduate School of Economics, Yonsei University (Master of Financial Engineering)

Feb. 2016: Graduate School of Industrial System Engineering, Gyeongsang National University (Doctor of Engineering)

Apr. 2013 present: Professor, Korea Lift College

Areas of interest: elevator, industrial engineering, IT design, elevator design automation, smart elevator, process innovation, smart manufacturing

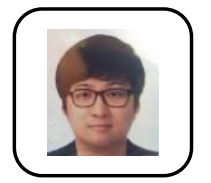

\section{Chang-Ki Hong}

Mar. 2001: Department of Mechanic Engineering (Inha University)

Director of Dae O Precision Engineering Co., Ltd

Areas of interest: elevator, tech. of explosion-proof, Lift

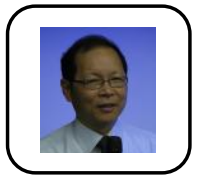

Soo-Chul Hwang

Feb. 1979: Department of Electronics (Kyungpook N University)

Feb. 1981: Graduate School of Kyunpook N. University (Master of Electronics)

Nov. 2009 present: Professor, Korea Lift College

Areas of interest: elevator design, elevator software design.

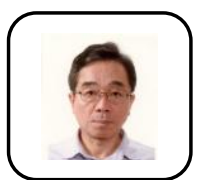

\section{Kwan-Hee Han}

1982: Department of Industrial Engineering (Ajou University)

1984: Korea Advanced Institute of Science and Technology Industrial Engineering (Master of Industrial Engineering)

1996: Department of Automation and Design Engineering, Korea Advanced Institute of Science and Technology (Doctor of Engineering)

Mar. 2003 Present: Professor, Department of Industrial Systems Engineering, Gyeongsang National University.

Areas of Interest: Business Process Management, Smart Factory, System Modeling / Simulation 